\title{
Desenvolvimento e Validação de Algoritmos para Emprego de Sensores na Soldagem Robótica Orbital do Passe de Raiz de Tubulações
}

\author{
Renan Medeiros Kindermann ${ }^{1}$, Régis Henrique Gonçalves e Silva ${ }^{1}$, Jair Carlos Dutra ${ }^{1}$ \\ 1 Laboratório de Soldagem - LABSOLDA, Departamento de Engenharia Mecânica, Universidade Federal de Santa Catarina - UFSC, \\ Florianópolis, SC, Brasil.
}

Recebido: 13 Nov., 2015

Aceito: 11 Dez., 2015

E-mail: renan.kindermann@labsolda. ufsc.br (RMK)
Resumo: Os sistemas comerciais destinados à automação da soldagem orbital enfrentam desafios perante o controle da trajetória e a parametrização do processo. Os tubos e dutos do setor de Petróleo e Gás apresentam descontinuidades, advindas de sua fabricação, críticas para o processo de soldagem. Para superar isto, o presente trabalho investiga a utilização de sensores para correção em tempo real da soldagem orbital. Um robô antropomórfico atua na condução da tocha. Um sensor a arco para seguimento de junta e um sensor baseado no contato elétrico para procura da junta foram empregados. Um programa em forma de algoritmos para geração de uma trajetória orbital automática e alocação dos parâmetros de soldagem foi desenvolvido. A validação da estratégia proposta e do controle da tocha pelo sensor a arco foi realizada com depósitos em corpos de prova de tubos. A soldagem do passe de raiz com um processo MIG/MAG com controle de corrente no curto-circuito também foi executada em conjunto com o sensor a arco.

Palavras-chave: Soldagem orbital; Soldagem robótica; Sensor a arco; MIG/MAG CCC.

\section{Development and Validation of Algorithms Employed for Sensor Systems in Robotic Orbital Root Pass Welding of Pipelines}

\begin{abstract}
The commercial welding systems for orbital welding automation face challenges regarding the robot path control and the process parameters. Pipes from oil and gas companies present discontinuities caused by the manufacturing stage that are critical for the welding process. To overcome this, the present paper investigates the use of sensors for real time correction in orbital welding. An anthropomorphous robot guides the torch. A through-arc sensor for seam tracking and an electrical contact sensor for seam finding were employed. A program for automatic path planning and welding parameters allocation was developed. The proposed strategy and the arc sensor torch control were validated based on weld deposits on pipe. The root pass welding was next performed using a short-circuit control GMAW process with the arc sensor.
\end{abstract}

Key-words: Orbital welding; Robotic welding; Through-arc sensor; GMAW CCC.

\section{Introdução}

As atuais soluções comerciais para automação da soldagem orbital se confrontam com alguns desafios. A manufatura dos tubos no estágio de preparação causam distorções, desalinhamentos e ovalizações, que por sua vez refletem em variações na abertura do chanfro e na posição da junta [1]. Com isto os parâmetros de soldagem e posicionamento da tocha não podem ser mantidos constantes durante toda a extensão do tubo.

Este estudo apresenta os resultados de um projeto que está sendo conduzido no laboratório de soldagem da Universidade Federal de Santa Catarina (LABSOLDA) em parceira com empresas do setor de petróleo e gás. O objetivo principal do projeto é o desenvolvimento de um robô antropomórfico destinado à soldagem de tubulações. Este robô será equipado com um sistema de sensoriamento de junta para correção em tempo real (online) da trajetória e compensação dos parâmetros de soldagem.

No início do projeto, a bancada de ensaios no LABSOLDA foi projetada em um software de simulação offline de trajetória. Entretanto, durante os ensaios de solda na bancada física, houve dificuldades de programação da trajetória não previstas na etapa inicial. Como esta era executada ponto a ponto pelo programador, um tempo considerável era despendido para o correto posicionamento da tocha na junta. Uma segunda etapa
Este é um artigo publicado em acesso aberto (Open Access) sob a licença Creative Commons Attribution Non-Commercial, que permite uso, distribuição e reprodução em qualquer meio, sem restriçōes desde que sem fins comerciais e que 0 trabalho original seja corretamente citado. 
do projeto foi, então, o desenvolvimento de um programa para soldagem orbital, de modo a tornar o processo mais automático e considerando a utilização de sensores.

O foco central do projeto é a utilização do sensor LASER como ferramenta de medição da junta. Entretanto, há tanto na literatura comum como nas indústrias, uma incerteza quanto à escolha do sensor mais adequado. Existe uma gama considerável de soluções de sensores para a soldagem a arco [2]. As patentes e publicações científicas nesta área de aplicação mostram que sensores LASER e sensores a arco baseado na corrente de solda estão substituindo antigos sistemas [3].

Sensores LASER possuem em geral maior precisão e fornecem também informações a respeito da geometria da junta. Em contrapartida, são mais caros e precisam ser montados diretamente na tocha, reduzindo o espaço de trabalho do robô. Além disto, a própria luz do arco pode interferir na análise da imagem. Sensores a arco, pelo contrário, são mais baratos, só que mais imprecisos e precisam necessariamente de um tecimento (oscilação da tocha), dado seu principio de funcionamento. Soma-se a isto, sua inerente dependência pela estabilidade do processo (em função da qualidade do sinal da corrente de solda).

Dado que instalado no robô deste trabalho (um Motoman HP20D) havia um módulo para seguimento e procura de junta, a validação do programa para soldagem orbital ocorreu incialmente com estes sensores. Atualmente, o projeto se encontra na etapa de desenvolvimento de algoritmos para a soldagem orbital com o sensor LASER. Este trabalho visa, no entanto, mostrar os resultados iniciais do projeto.

\section{Aparato Experimental}

Sob a ótica de processos de soldagem, a solda neste trabalho é realizada basicamente por dois subsistemas: uma fonte de soldagem e um robô antropomórfico industrial. Este último é do tipo Motoman HP20D, fabricado pela empresa YASKAWA (Figura 1). A sua estrutura cinemática é do tipo articulado vertical com 6 graus de liberdade. A fonte de soldagem é do tipo Digiplus A7, da fabricante brasileira IMC. Sua capacidade máxima de corrente é de $450 \mathrm{~A}$. O processo de soldagem utilizado neste trabalho é o MIG/MAG com curto-circuito controlado, com nome comercial de CCC. O CCC apresenta um controle sinérgico do arco por meio da corrente de solda. Para tanto, o controle da corrente é determinado eletronicamente com base na leitura instantânea da tensão. Este processo foi desenvolvido no LABSOLDA [4,5].

A unidade controladora do robô é do modelo DX100 e a linguagem de programação é chamada de INFORM III [6]. Para comunicação com outros equipamentos são previstas 40 entradas e 40 saídas digitais. Além disto, uma placa eletrônica instalada à parte, a JANCD-YEW01-E, permite também uma comunicação analógica, por meio de duas portas I/O. Neste trabalho, dois parâmetros da linha sinérgica do processo CCC, a altura do arco e a velocidade de arame, eram controlados pelo robô por meio das portas analógicas.

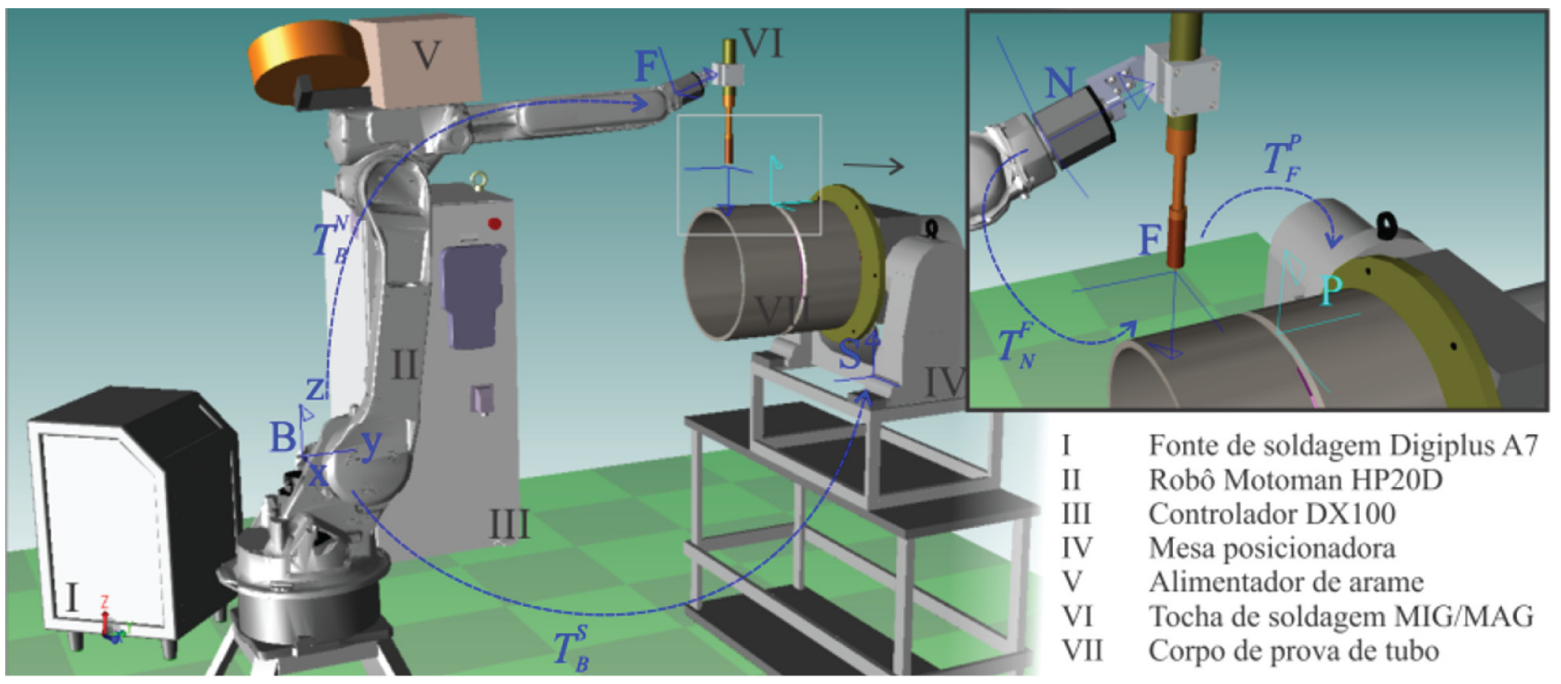

Figura 1. Simulação da bancada de ensaios e definição dos sistemas de coordenadas na soldagem orbital robotizada. 
Desenvolvimento e Validação de Algoritmos para Emprego de Sensores na Soldagem Robótica Orbital do Passe de Raiz de Tubulações

Em uma unidade adicional encontra-se instalado o COMARC III. Esta unidade possui dois tipos de sensores: um sensor de seguimento de junta a arco, chamado de COMARC, e um sensor de procura de junta baseado no contato elétrico, com nome comercial de TOUCHSENSE.

\section{Simulação da Bancada de Ensaios}

A Figura 1 mostra a visualização da bancada de ensaios projetada em um ambiente virtual. A simulação mostrou-se necessária para correta determinação do movimento do robô ao redor do tubo. Inicialmente, a posição do tubo relativo ao robô e o projeto do suporte de tocha não eram adequados. Ocorriam singularidades no braço robótico que limitavam seu espaço de trabalho. Desta forma, uma trajetória orbital no tubo não era possível. Com a simulação, o correto projeto dos componentes físicos da bancada foi facilitado.

O suporte de tocha projetado é visto na Figura 2. É mostrada também uma câmera para observação do processo de soldagem, que é posicionada em torno de $170 \mathrm{~mm}$ à frente da tocha. Esta câmera possui um sensor CMOS que permite a captura das imagens. Seu nome comercial é seelectorICAM weld, sendo fabricada pela empresa $H E M A$ eletrectonics $\mathrm{GmbH}$. Durante os ensaios, ela foi importante para verificar a estabilidade do processo e visualizar o alinhamento da tocha na junta.

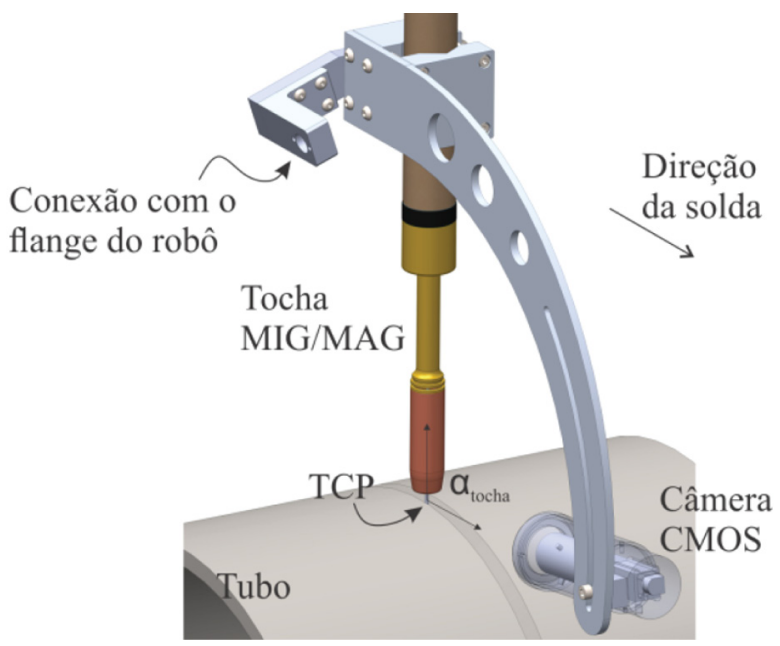

Figura 2. Projeto do suporte de tocha com uma câmera CCD para observação da solda. O ângulo de trabalho, $\alpha_{\text {tocha }}$, é rotação em torno do TCP.

Ainda na Figura 2, o ângulo de trabalho da tocha, convencionado como $\alpha_{\text {tocha' }}$ é estabelecido como sendo o ângulo entre a linha tangente ao tubo e a linha com mesma direção que a tocha. Na soldagem orbital, é importante que o ângulo de trabalho da tocha, definido pela própria postura da tocha, seja controlado pelo robô com precisão. Desta forma, garante-se que o mesmo se mantenha constante dentro de um valor fixado pelo procedimento de soldagem.

Para manipulação precisa do robô e interpolação dos pontos de uma trajetória é necessário que o robô reconheça o sistema de coordenadas da ponta da ferramenta, onde fica localizado o TCP (ponto central da ferramenta, do inglês "tool center point"). Para tanto ocorrem transformações entre os sistemas de coordenadas descritos na Figura 1.

Uma transformação descreve a localização (posição e orientação) de um sistema de coordenadas com respeito a outro sistema referencial. Transformações são indicadas pelo símbolo $T$ com o sobrescrito que define o sistema de referência.

Na Figura 1 os seguintes sistemas de coordenadas são definidos: 
- B: Base. Referenciado na base do robô e não se movimenta em relação ao ambiente.

- S: Mesa posicionadora. Diz respeito à base da mesa posicionadora, que no presente trabalho possui 2 graus de liberdade. Como a soldagem em campo não permite a rotação do tubo, a mesa posicionadora só atuou na fixação e permanecia, portanto, imóvel durante o processo. A transformação $T_{B}^{S}$ descreve $\mathrm{S}$ com respeito à $\mathrm{B}$.

- N: Flange. Sistema de coordenadas localizado no flange (end effector) do robô, onde o suporte de tocha é conectado (Figura 2). A transformação $T_{B}^{N}$ relaciona o flange à base do robô.

- F: Ferramenta/tocha. É localizado na extensão livre do arame de adição de uma tocha automática do processo MIG/MAG. Esta extensão é conhecida como distância do bico de contato à peça (DBCP). A transformação $T_{N}^{F}$ descreve $\mathrm{F}$ em relação ao $\mathrm{N}$.

- J: Junta. Localizado em uma região do tubo a ser definida pelo usuário. Neste trabalho a posição de J se encontrava definida na própria trajetória do robô (na junta). A transformação $T_{F}^{J}$ descreve J em relação à $\mathrm{F}$.

\section{Programa para Soldagem Orbital}

Para automatizar a trajetória orbital em um robô industrial, dividiu-se o programa, conhecido como job, em sub-rotinas e funções. Inicialmente, programou-se uma função para atualizar a posição da tocha em relação ao tubo com base em uma variável contadora (variável I). Desta forma, os parâmetros e variáveis do processo de soldagem podem ser atualizados e ordenados de acordo com a atual posição da tocha no tubo.

Cada posição do tubo é por sua vez determinada com base em um segmento de ângulo da trajetória semicircular ( 0 a 180 ) $)$. O segmento é definido no inicio do programa pelo parâmetro $\beta_{\text {seg }}$. A Figura 3 ilustra a divisão da trajetória para um $\beta_{\text {seg }}$ definido em 15ㅇ.

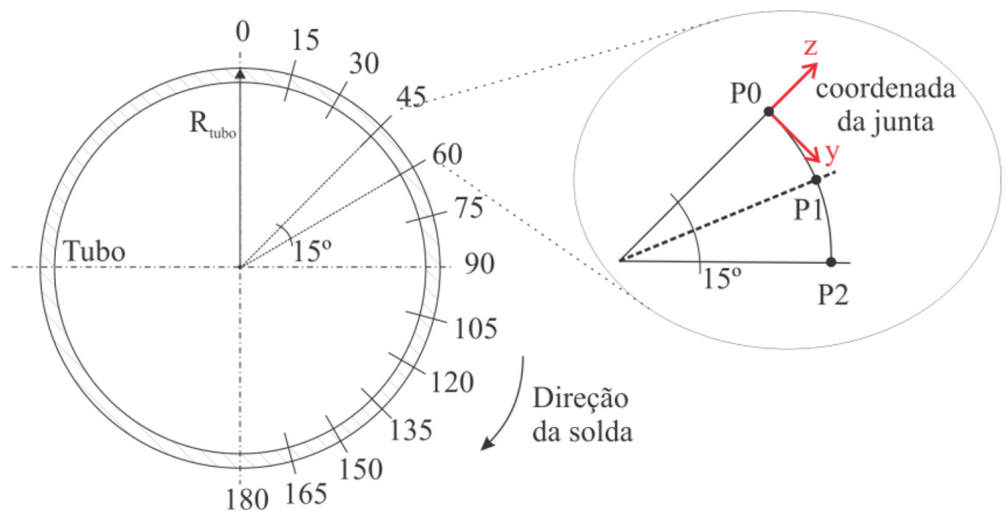

Figura 3. Estratégia de divisão da trajetória orbital em segmentos de círculo.

Utilizando funções/variáveis aritméticas para descrever pontos de uma circunferência no espaço do robô, a trajetória orbital é programada ao redor do tubo. Neste caso, leva-se em consideração o raio externo do tubo, $R_{\text {tubo }}$. Utilizando esta abordagem não é mais necessário que a tocha seja manualmente conduzida pelo operador para salvar os pontos ao redor do tubo (programação ponto a ponto).

No controlador do robô, um movimento circular é descrito por intermédio da interpolação de no mínimo três pontos. Logo, para cada segmento são programadas três posições, denominadas de P0, P1 e P2, que correspondem, respectivamente, ao ponto inicial, ponto médio e ponto final do segmento em questão.

Com o intuito de simplificar a programação, no inicio de cada segmento um sistema de coordenada da junta é atualizado, cuja direção $z$ é perpendicular à superfície do tubo e direção y tangente a ela. Assim, as coordenadas cartesianas de cada ponto servem igualmente para todos os segmentos. A programação dos pontos é facilitada, já que uma função loop pode ser utilizada. 
Desenvolvimento e Validação de Algoritmos para Emprego de Sensores na Soldagem Robótica Orbital do Passe de Raiz de Tubulações

A postura da tocha é alterada a fim de que mantenha o ângulo de trabalho, $\alpha_{\text {tocha' }}$, constante. Neste caso, outra sub-rotina em função da variável I realiza este cálculo.

O fluxograma da Figura 4 mostra a lógica de funcionamento empregada no programa para soldagem orbital com sensores. Durante a inicialização o usuário define os parâmetros de entrada que são: o ângulo de trabalho da tocha, $\alpha_{\text {tocha }}$ o ponto inicial da rotina de procura de junta, $P_{\text {inicial, }}$ o raio externo do tubo, $R_{\text {tubo }}$, e o ângulo de divisão da trajetória, $\beta_{\text {seg }}$. O programa não leva em consideração a DBCP. Esta é definida pela rotina de procura da junta, sendo estipulada durante a calibração/configuração do sensor escolhido.

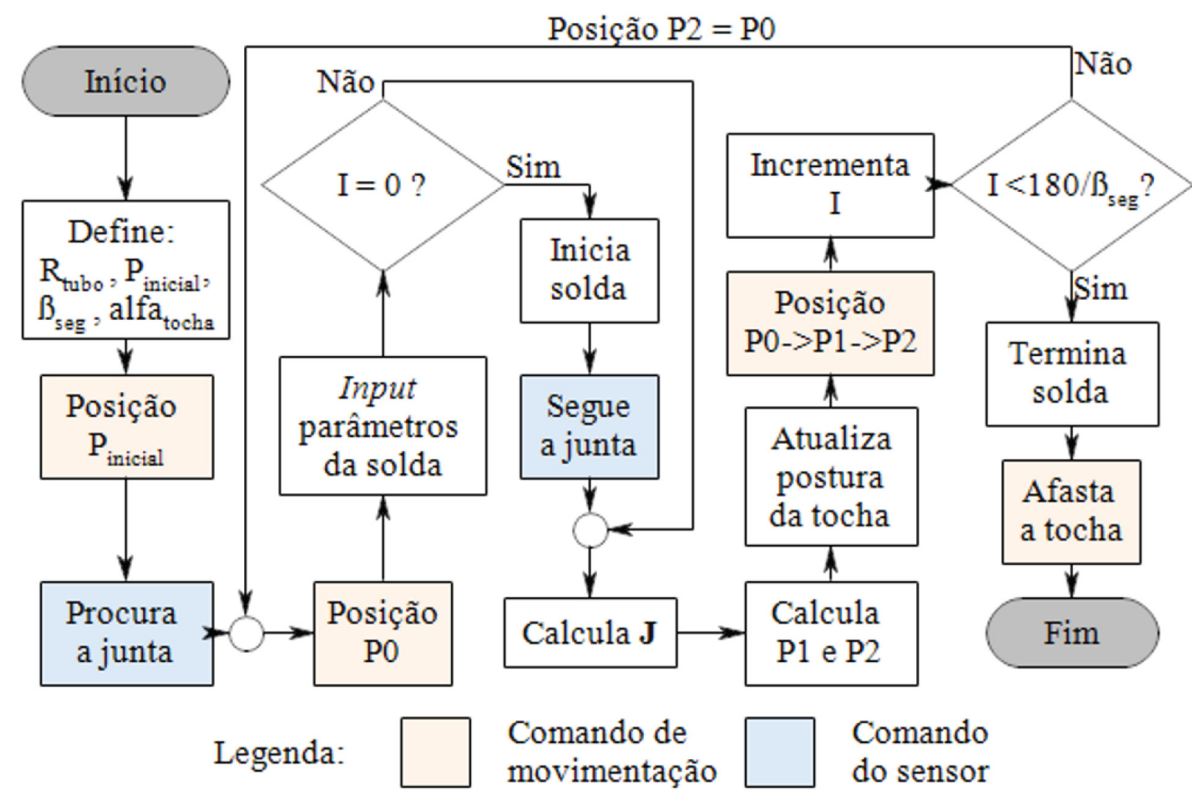

Figura 4. Fluxograma do funcionamento do programa para soldagem orbital com sensoriamento de junta em um robô industrial.

Com o inicio do processo, o robô movimenta-se para $\mathrm{P}_{\text {inicial’ }}$ onde a rotina de procura de junta é executada. Esta pode ser executada com base em um sensor de toque ou em um sensor LASER, por exemplo. Quando o chanfro é encontrado, a posição PO é atualizada. Neste momento, I é igual à zero, situação que define o início da solda com tecimento e seguimento da junta (via sensor a arco ou LASER). Na sequência, calcula-se o sistema de coordenada da junta e os próximos pontos do segmento, P1 e P2. No fim do segmento, I é incrementado, e a posição P2 corresponde à P0 do novo segmento. Os parâmetros de solda são novamente definidos e o processo de soldagem prolonga-se até o momento em que todos os segmentos sejam executados.

Da forma que o programa foi estruturado, os parâmetros de soldagem podem ser ordenados com relação à variável I para cada segmento. Os parâmetros escolhidos para a soldagem orbital foram:

1. Velocidade de soldagem;

2. Amplitude de tecimento;

3. Frequência de tecimento;

4. Tempo de parada;

5. Velocidade de arame;

6. Correção da altura do arco.

Os quatros primeiros parâmetros dizem respeito à movimentação do robô e os dois últimos às variáveis do processo sinérgico MIG/MAG CCC. 
Caso se utilize um sensor que forneça informações a respeito da geometria da junta (um dos objetivos principais do projeto), como um sensor LASER, os parâmetros calculados neste modo adaptativo seriam fornecidos para o robô nesta etapa. Nos ensaios com o sensor a arco os parâmetros foram, no entanto, manualmente configurados (input pelo usuário).

\section{Procura da Junta com Sensor de Contato Elétrico}

Este tipo de sensor utiliza rotinas de movimentação programáveis com a própria linguagem do controlador (INFORM III). A posição do tubo no espaço é determinada por intermédio do avanço da tocha de soldagem em direção ao tubo, até o momento em que um contato elétrico seja detectado. Um sinal elétrico de $220 \mathrm{~V}$ é empregado para este fim. A Figura 5 mostra uma ilustração para entendimento da rotina de procura da junta. O sistema de coordenadas definido em $\{x, y, z\}$ é um plano arbitrário definido na peça.

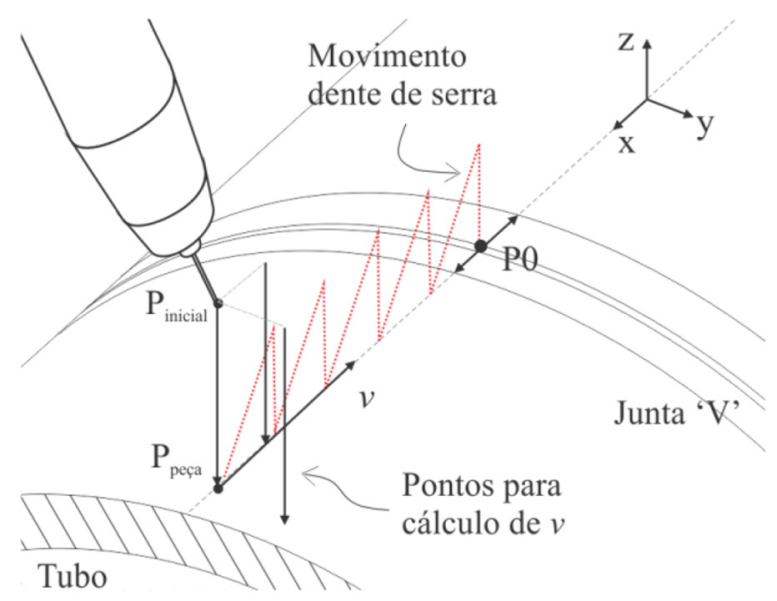

Figura 5. Rotina de detecção do inicio da junta utilizando um sensor de contato elétrico na soldagem de tubulações.

O único ponto programável pelo usuário é o ponto onde se inicia a rotina de detecção, chamado de $P_{\text {inicial }}$. A partir deste ponto o robô avança linearmente a tocha em direção à superfície do tubo. A DBCP fica definida com base no comprimento de eletrodo livre que primeiro toca o tubo. Este ponto é convencionado como $P_{\text {peça. }}$ Na sequência, a rotina de detecção toca o tubo mais duas vezes, com deslocamentos programados nas direções dos eixos $x$ e $y$. Com base nestas três posições, é calculado um vetor $v$ que corresponde à direção do inicio da junta. Isto é realizado para que haja uma compensação caso o tubo esteja levemente rotacionado em torno da coordenada y (tubo desnivelado).

Em seguida, o robô movimenta-se em direção ao inicio da junta em movimentos com forma de dente de serra. Este tipo de movimento é utilizado devido à própria geometria do chanfro que está sendo procurado. Neste caso, ele é detectado quando a profundidade em relação à linha base da superfície da peça ultrapassa um valor pré-determinado.

Depois da detecção de profundidade, o robô toca linearmente as duas extremidades do chanfro para determinar o ponto médio da junta, PO. O ponto PO é escolhido como o ponto inicial da solda.

É ainda possível salvar a medida da abertura superior do chanfro e utilizá-la como forma de ajustar a amplitude de tecimento. Neste trabalho, no entanto, não houve compensação da amplitude baseado no sensor de contato elétrico. Como a variação dimensional da junta presenciada na preparação dos tubos é geralmente grande, apenas uma medida não seria suficiente (aqui seria mais recomendado um sensor LASER, que apresenta medição online).

\section{Metodologia dos Ensaios com Solda}

A Tabela 1 mostra os parâmetros utilizados nos ensaios para validação e avaliação do programa para soldagem orbital com seguimento de junta a arco. Os parâmetros foram mantidos constantes para todas as posições do tubo. Como forma de avaliar o controle do sensor a arco adquiriu-se os sinais elétricos durante a solda. A taxa de aquisição é de $5 \mathrm{kHz}$. 
Desenvolvimento e Validação de Algoritmos para Emprego de Sensores na Soldagem Robótica Orbital do Passe de Raiz de Tubulações

Tabela 1. Parâmetros e variáveis de soldagem nos ensaios com seguimento de junta via sensor a arco.

\begin{tabular}{lcc}
\hline \multicolumn{1}{c}{ Parâmetro/variável } & Valor & Unidade \\
Velocidade de arame & 3,5 & $\mathrm{~m} / \mathrm{min}$ \\
Velocidade de soldagem & 0,2 & $\mathrm{~m} / \mathrm{min}$ \\
Corrente média* & 130 & $\mathrm{~A}$ \\
Frequência de tecimento & 2,0 & $\mathrm{~Hz}$ \\
Amplitude de tecimento & 3,0 & $\mathrm{~mm}$ \\
DBCP objetivada & $\mathrm{mm}$ & 17 \\
Diâmetro do arame & 1,2 & $\mathrm{~mm}$ \\
Tipo do arame & ER70S-6 & - \\
Composição do Gás & Ar- 25\% CO2 & - \\
Vazão de gás aproximada & 15 & $\mathrm{~L} / \mathrm{min}$ \\
\hline
\end{tabular}

Nota: *Corrente média de referência configurada no sensor a arco.

Para os ensaios do passe de raiz, as extremidades do tubo foram preparadas com um chanfro em $V$ com ângulo de bisel de 30․ A abertura da raiz apresentou uma faixa de variação da ordem de 2 a $3 \mathrm{~mm}$. Ressalta-se que não há o emprego de ferramentas para a sustentação da poça de fusão como, por exemplo, um backing.

\section{Seguimento de Junta com Sensor a Arco}

A Figura 6 apresenta imagens da poça de fusão em três momentos distintos de uma mesma solda do passe de raiz. Neste ensaio utiliza-se o sensor a arco baseado no controle da corrente para seguimento de junta. O objetivo da Figura 6 é mostrar os desalinhamentos presenciados durante a soldagem para validação do sensor a arco como seguimento de junta com o programa desenvolvido (item 4).

No primeiro momento a tocha está desalinhada em relação à linha central da junta (linha pontilhada branca). Na extremidade esquerda do tecimento é mostrada uma situação onde o arco é diretamente direcionado à parede do chanfro. Sem o ancoramento da poça de fusão, o processo de soldagem é desestabilizado. Principalmente em processos MIG/MAG com controle intrínseco do arco, como o CCC, é fundamental que o arco incida diretamente sobre a poça de fusão. Caso contrário, a detecção da reabertura do arco é prejudicada e a gota tende a crescer excessivamente.

Na sequência da Figura 6, é mostrada uma situação de tocha centralizada na junta com o arco ancorado na poça e processo estável. No último conjunto de imagens outra situação de desalinhamento, desta vez no lado contrário ao inicial. A instabilidade do processo é novamente presenciada.

Na Figura 7 é apresentado o aspecto superficial de dois cordões do passe de raiz no tubo com seguimento de junta a arco incorreto. Aparentemente o seguimento se comportava bem até o momento em que a tocha alcançava as posições próximas à vertical descendente (em torno de 60으. Neste momento apenas uma análise qualitativa foi realizada.

Como não houve meios de utilizar o sensor a arco em todo o perímetro do tubo, hipóteses foram levantadas para entender o problema. Inicialmente, como forma de simplificar o controle a ser realizado pelo sensor a arco, a correção lateral da tocha foi desativada. No caso, soldou-se sobre a superfície do tubo (sem ser dentro do chanfro), onde apenas as correções na altura da tocha (controle da DBCP) eram realizadas. O movimento de tecimento foi mantido, todavia, não seria obrigatoriamente necessário. Para viabilizar o ensaio foi necessário desligar o sensor a arco na posição vertical descendente (referente à posição de 60 a 120ㅇ na Figura 3).

Durante os ensaios adquiriu-se a corrente instantânea de solda. Devido à natureza altamente dinâmica dos sinais elétricos da soldagem por curto-circuito um condicionamento da leitura da corrente se faz necessário. Desta forma, uma interpretação mais clara das condições da soldagem é possível.

Quando o sinal é filtrado, a variação da corrente é pequena, restando, basicamente, a variação ocasionada pela movimentação da tocha. Em seu trabalho, Mendonça [7], emprega um filtro passa-baixa com frequência de corte, $f_{\sigma^{\prime}}$ de $1,54 \mathrm{~Hz}$. A mesma frequência foi escolhida neste trabalho, só que neste caso utiliza-se aqui um filtro 
Situação de tocha desalinhada para a esquerda:

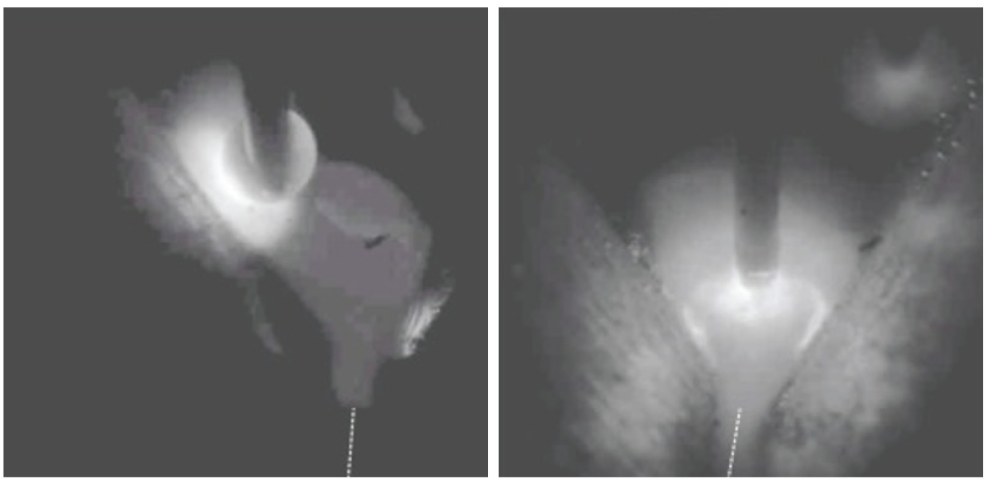

Situação de tocha centralizada:
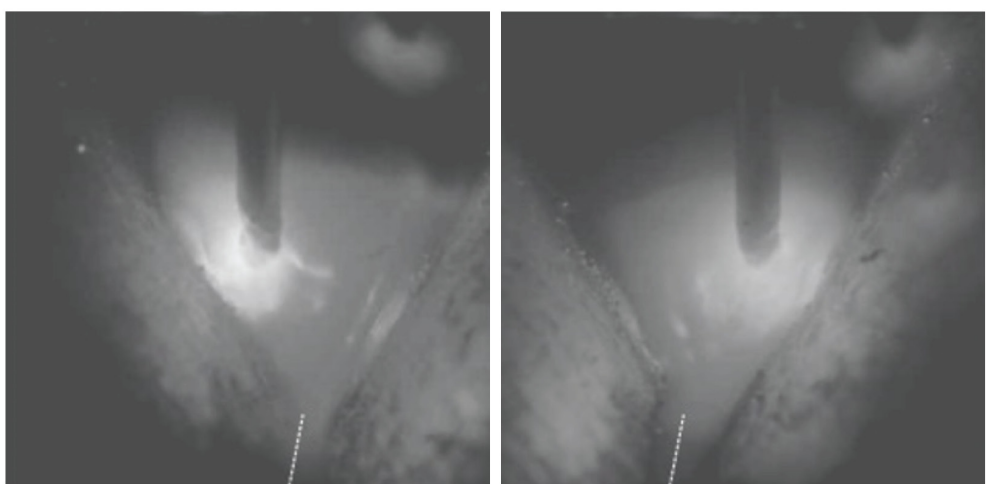

Situação de tocha desalinhada para a direita:
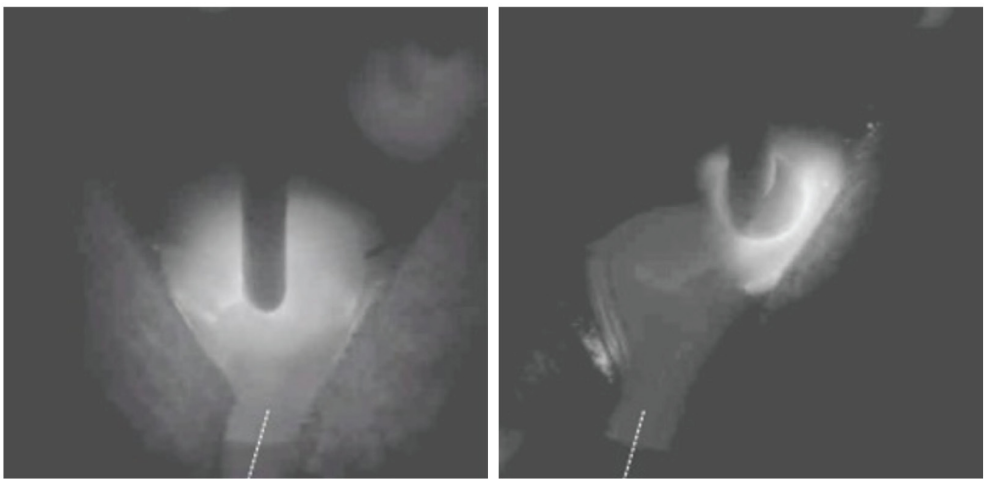

Figura 6. Imagens da poça de fusão durante a soldagem do tubo com seguimento de junta incorreto.

Cordão A:

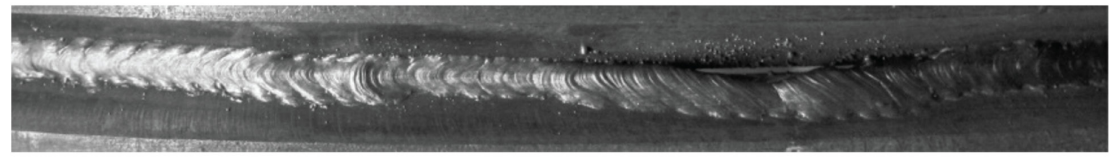

Cordão B:

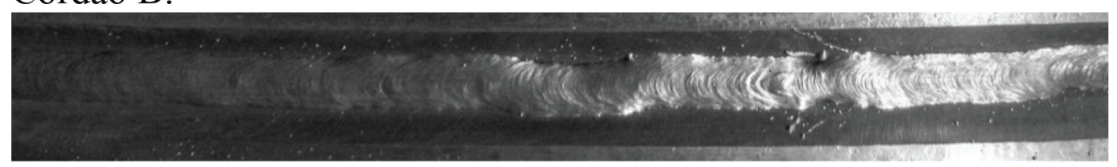

Figura 7. Aspecto superficial de dois cordões do passe de raiz utilizando sensoriamento de junta a arco nas posições próximas à vertical descendente. 
Desenvolvimento e Validação de Algoritmos para Emprego de Sensores na Soldagem Robótica Orbital do Passe de Raiz de Tubulações

digital (via software). A Figura 8 mostra o resultado em forma de gráfico para cada posição no tubo. A posição no tubo foi obtida indiretamente com base no tempo e velocidade de solda.

A corrente de soldagem configurada no sensor a arco foi de $130 \mathrm{~A}$. No caso, a altura da tocha é regulada até que a DBCP seja tal que se alcancem aproximadamente os $130 \mathrm{~A}$. A lógica empregada pelo sensor estudado para reposicionamento da tocha de soldagem, é conhecida como "liga-desliga com histerese", um conceito relativamente simples na área de controle, conforme explica Mendonça [7].

A Figura 8 mostra que na região inicial do tubo, até em torno de 80 , a corrente média se mantém próxima do patamar de $130 \mathrm{~A}$. Como a partir de 60 o o sensor foi desligado, a altura da tocha parou de ser controlada e houve um aumento da corrente de solda. No programa orbital, a última posição de cada segmento (P2) é tomada como ponto inicial para próximo segmento (PO). Logo, quando o sensor a arco é desligado, a posição da tocha esta correta e a partir de então, é considerada uma trajetória circular perfeita. Pelo fato do tubo ser ovalizado, sem um controle da posição da tocha, houve neste caso uma redução da DBCP, com um consequente aumento da corrente. Quando o sensor a arco é novamente religado na posição sobre cabeça a tocha é controlada para que se obtenham novamente os $130 \mathrm{~A}$.

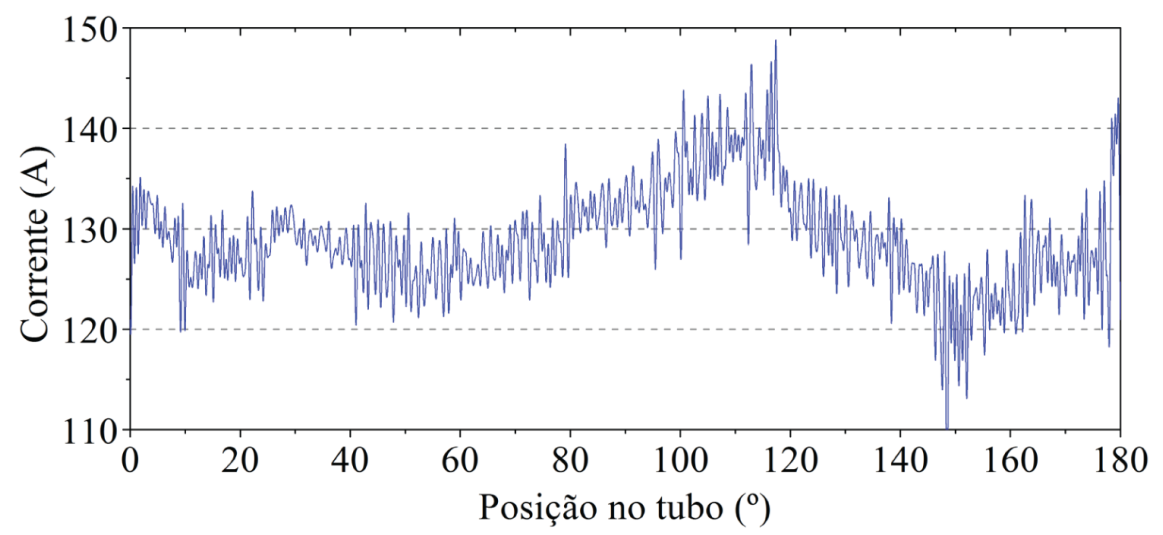

Figura 8. Variação da corrente durante a soldagem sobre o tubo com o sensor a arco. 0 sinal da corrente foi filtrado digitalmente com um filtro passa-baixa $\operatorname{com} f_{0}=1,54 \mathrm{~Hz}$.

A explicação para o fato de não ser possível o uso do sensor em posições, neste caso, mais criticas como a vertical descendente foi encontrada mais precisamente no trabalho de Fridenfalk [8]. $O$ autor desenvolveu um sensor a arco para robôs antropomórficos num projeto europeu chamado de ROWER-2. Neste sensor, são possíveis correções de trajetórias mais complexas que as lineares, como no nosso exemplo, uma trajetória orbital. Segundo o autor, o seguimento de junta em robôs antropomórficos industriais é atualmente conduzido somente em 2D. Geralmente a posição da tocha, definida pelo TCP, é corrigida em um plano ortogonal à direção da junta. A Figura 9 ilustra esta afirmação.

O sistema ortogonal $\{h, t, w\}$ é gerado no inicio do movimento, quando a tocha está se aproximando da junta. É importante ressaltar que ele não é atualizado durante a mudança de postura da tocha, quando a mesma está se deslocando (e rotacionando) ao redor do tubo. Sendo assim, afirma-se que este princípio de correção é somente válido para trajetórias sem curvaturas muito acentuadas, onde a postura da tocha não é significativamente alterada.

Em trajetórias do tipo circular ou spline, a correção do sensor a arco que é referenciada ao sistema $\{h, t, w\}$ não é confiável. Isto explica o fato de na Figura 8, nas posições em torno de 90ㅇ, quando a tocha está perpendicular ao plano $\{h, t, w\}$, as correções do sensor a arco apresentarem um comportamento anômalo (fenômeno visualizado pela variação da corrente). Da mesma forma, explicam-se os resultados da solda vistos na Figura 6 e Figura 7, onde houve a perda de seguimento da junta pelo robô.

Esta particularidade do sensor foi apenas notória durante os ensaios, já que o manual do fabricante não deixa isto claro. 


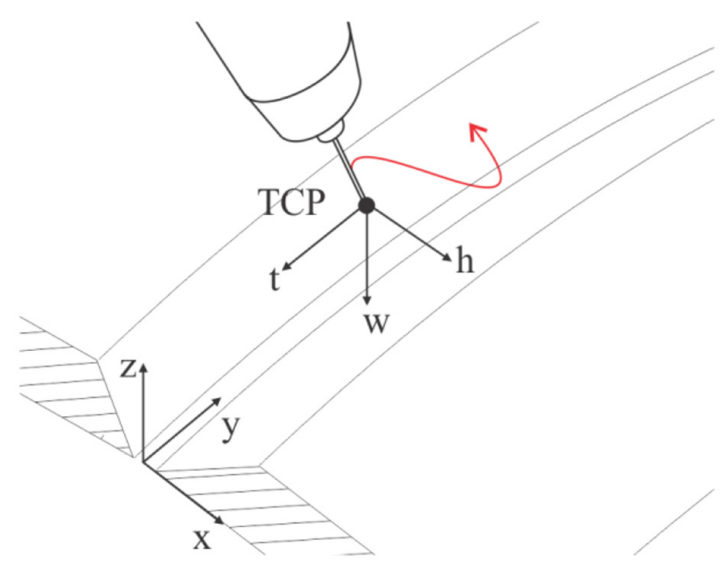

Figura 9. Definição do TCP e do sistema de coordenadas ortogonal $\{h, t, w\}$. O tecimento é conduzido na direção do eixo $h$, $t$ possui direção oposto à de soldagem e w é a direção de aproximação.

\section{Avaliação do Processo CCC com Sensor a Arco}

Apesar de a literatura comum restringir muitas vezes a utilização do sensor a arco baseado na corrente para o processo MIG/MAG convencional (com controle em tensão), neste trabalhou foi possível a sua utilização em um processo com controle interno da corrente de solda.

Para explicar esta afirmação é mostrado inicialmente a Figura 10. Nela é apresentado o oscilograma de tensão e corrente para o processo CCC. São também mostradas algumas variáveis de corrente e de tempo. Estas variáveis são carregadas automaticamente pelo programa da fonte de soldagem (no modo sinérgico), que por sua vez dependem da velocidade de arame e altura do arco selecionada pelo programa.

As variáveis de corrente da linha sinérgica $\mathrm{I}_{\mathrm{p}}$ (corrente de pulso), $\mathrm{I}_{\mathrm{Pm}}$ (corrente de patamar médio) e $\mathrm{I}_{\mathrm{B}}$ (corrente de base) não se alteram ao longo da soldagem. Assim como as variáveis de tempo: $t_{\mathrm{p}}$ (tempo de pulso) e $t_{\mathrm{pm}}$ (tempo de patamar médio). Entretanto, determinadas variáveis, como $\mathrm{I}_{c c}$ (corrente de curto-circuito) e $\mathrm{t}_{\mathrm{cc}}$ (tempo de curto-circuito), não podem ser estipuladas com base em um valor fixo. Isto é explicado pela física do arco em curto-circuito e a dinâmica da poça de fusão durante os períodos de abertura e reabertura do arco. Da mesma forma, a variável de tempo $t_{B}$ precisa se ajustar às condições físicas do arco. Por intermédio dela, a velocidade de fusão do arame é compensada com base em sua velocidade de aproximação à poça.

A Figura 11 mostra uma situação de solda dentro do chanfro com o processo CCC. O sinal foi novamente filtrado via software para mostrar a variação da corrente de solda. As correções do sensor a arco são baseadas nas variações de corrente média. Estas variações são ocasionadas, por sua vez, devido às diferentes velocidades

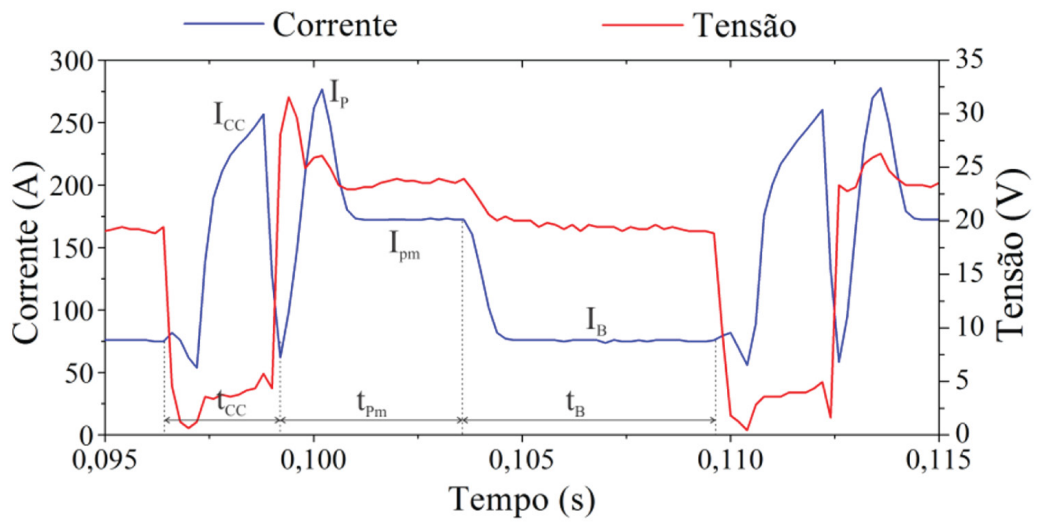

Figura 10. Gráfico da variação de corrente com o tempo para o processo MIG/MAG CCC com a definição das variáveis do programa sinérgico. 
Desenvolvimento e Validação de Algoritmos para Emprego de Sensores na Soldagem Robótica Orbital do Passe de Raiz de Tubulações

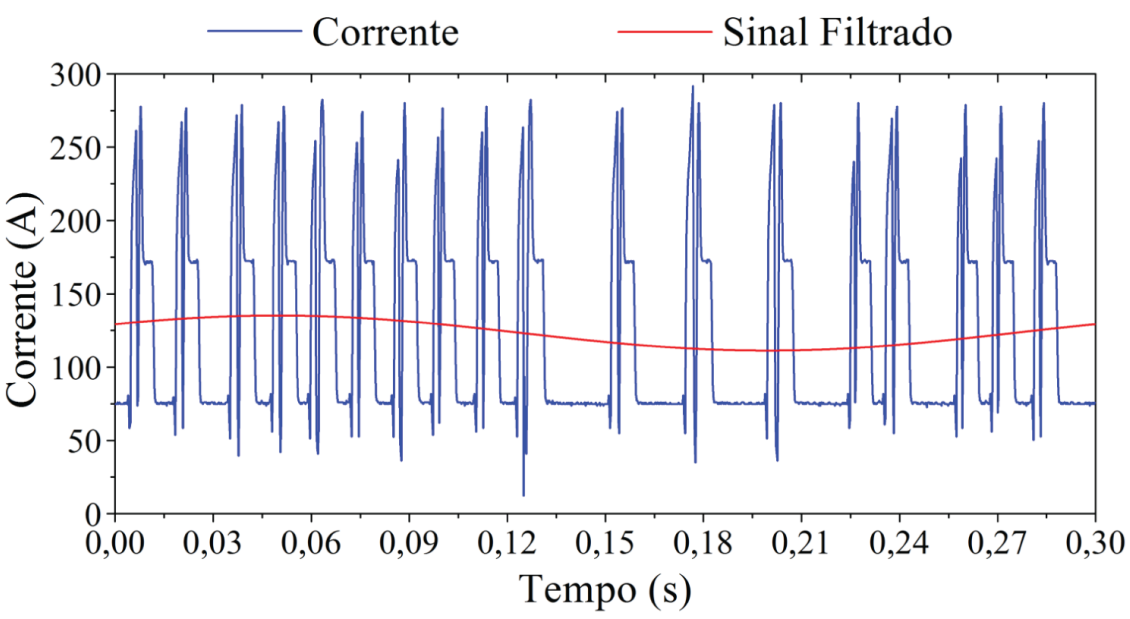

Figura 11. Soldagem dentro de um chanfro e com tecimento com o processo CCC. O sinal foi condicionado com um filtro digital.

de aproximação do arame à poça quando a tocha oscila dentro do chanfro. Na soldagem com o processo CCC, as diferentes velocidades de aproximação do arame fazem com que haja um consequente aumento/diminuição da frequência de curtos-circuitos. Fisicamente o processo se desestabilizaria caso o $t_{B}$ permanecesse fixo.

Desta forma, o sensor a arco interpreta esta variação na corrente, atuando nas correções de forma semelhante a um processo MIG/MAG controlado em tensão. Ressalta-se que conforme o principio de funcionamento do sensor a arco, para correção lateral da tocha, o tecimento é compulsoriamente necessário (para que uma variação da corrente média seja provocada).

\section{Conclusão}

Com base nos resultados e discussões aqui apresentados, as conclusões deste trabalho podem ser resumidas conforme segue:

- Foi considerada inviável a utilização de um sensor a arco comercial baseado na corrente para a soldagem orbital robotizada. Isto se deve ao fato de o sensor ser fundamentalmente 2D e não permitir a utilização em trajetórias com curvatura acentuada.

- Da mesma forma que afirma Fridenfalk [8], o uso de um processo de soldagem MIG/MAG com controle interno da corrente de solda (curto-circuito controlado) é possível com o sensor a arco.

- O sensor de contato elétrico para procura da junta foi adequado para a soldagem de tubulações. Uma vez que toda a lógica de programação é elaborada, sua execução acontece de forma simples e confiável.

\section{Agradecimentos}

Os autores gostariam de agradecer a ANP/Petrobras pela concessão de bolsas e as empresas IMC e SPS pela prestação de serviços e apoio prestados.

\section{Referências}

[1] Bae KY, Lee TH, Ahn KC. An optical sensing system for seam tracking and weld pool control in gas metal arc welding of steel pipe. Journal of Materials Processing Technology. 2002;120(1-3):458-465. http://dx.doi.org/10.1016/S09240136(01)01216-X.

[2] Deutscher Verband für Schweißen und verwandte VerfahrenDVS. Sensoren für das vollmechanische Lichtbogenschweißen. Düsseldorf; 2005. 8 p.

[3] Fridenfalk M, Bolmsjo G. Design and validation of a universal $6 \mathrm{D}$ seam-tracking system in robotic welding using arc sensing. Advanced Robotics. 2004;18(1):1-21. http://dx.doi. org/10.1163/156855304322753272.

[4] Silva RHG. Controlled short-circuiting MIG/MAG welding (CCC): process analysis tools. Welding and Cutting. 2009;(3):162-167.

[5] Direne HF. Comparação do processo MIG/MAG em transferência por Curto-circuito com Controle de Corrente (CCC) com o 
processo STT na soldagem de passes de raiz em dutos. Brasília: Agência Nacional do Petróleo, Gás Natural e Biocombustíveis; 2013. (Informe Conjuntura \& Informação, 63).

[6] Motoman. DX100 Options Instructions for INFORM Language. West Carrollton: Yaskawa America Inc.; [2000?]. 301 p.

[7] Mendonça FK. Evolução da técnica de seguimento de junta via sensoriamento do arco para operações de soldagem em posições forçadas [tese de doutorado]. Florianópolis: Departamento de Engenharia Mecânica, Universidade Federal de Santa Catarina; 2013.

[8] Fridenfalk M. Development of intelligent robot systems based on sensor control [tese de doutorado]. Sweden: Department of Mechanical Engineering, Division of Robotics, Lund University; 2003. 